\title{
Polyvariant Mutant Cystic Fibrosis Transmembrane Conductance Regulator Genes The Polymorphic (TG)m Locus Explains the Partial Penetrance of the T5 Polymorphism as a Disease Mutation
}

\author{
Harry Cuppens, ${ }^{*}$ Wei Lin, ${ }^{\ddagger}$ Martine Jaspers, ${ }^{*}$ Bruno Costes, ${ }^{\S}$ Hui Teng, ${ }^{*}$ Anne Vankeerberghen, ${ }^{*}$ Mark Jorissen," \\ Guy Droogmans, ${ }^{\ddagger}$ Ingrid Reynaert, ${ }^{*}$ Michel Goossens, ${ }^{\circledR}$ Bernd Nilius, ${ }^{\ddagger}$ and Jean-Jacques Cassiman* \\ *Center for Human Genetics, KULeuven, B-3000 Leuven, Belgium; ${ }^{\ddagger}$ Department of Physiology, KULeuven, B-3000 Leuven, Belgium;

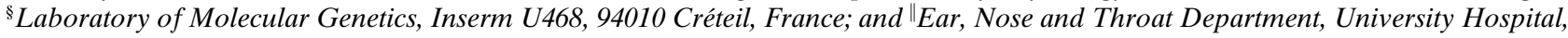 \\ B-3000 Leuven, Belgium
}

\begin{abstract}
In congenital bilateral absence of the vas deferens patients, the T5 allele at the polymorphic Tn locus in the CFTR (cystic fibrosis transmembrane conductance regulator) gene is a frequent disease mutation with incomplete penetrance. This T5 allele will result in a high proportion of CFTR transcripts that lack exon 9, whose translation products will not contribute to apical chloride channel activity. Besides the polymorphic Tn locus, more than 120 polymorphisms have been described in the CFTR gene. We hypothesized that the combination of particular alleles at several polymorphic loci might result in less functional or even insufficient CFTR protein. Analysis of three polymorphic loci with frequent alleles in the general population showed that, in addition to the known effect of the Tn locus, the quantity and quality of CFTR transcripts and/or proteins was affected by two other polymorphic loci: (TG)m and M470V. On a T7 background, the (TG)11 allele gave a 2.8 -fold increase in the proportion of CFTR transcripts that lacked exon 9, and (TG)12 gave a sixfold increase, compared with the (TG)10 allele. T5 CFTR genes derived from patients were found to carry a high number of TG repeats, while T5 CFTR genes derived from healthy CF fathers harbored a low number of TG repeats. Moreover, it was found that M470 CFTR proteins matured more slowly, and that they had a 1.7-fold increased intrinsic chloride channel activity compared with V470 CFTR proteins, suggesting that the M470V locus might also play a role in the partial penetrance of T5 as a disease mutation. Such polyvariant mutant genes could explain why apparently normal CFTR genes cause disease. Moreover, they might be responsible for variation in the phenotypic expression of CFTR mutations, and be of relevance in other genetic diseases. (J. Clin. Invest. 1998. 101:487-496.) Key words: cystic fibrosis trans-
\end{abstract}

Address correspondence to Harry Cuppens, Center for Human Genetics, Campus Gasthuisberg O\&N6, Herestraat 49, B-3000 Leuven, Belgium. Phone: 32-16-346070; FAX: 32-16-345997; E-mail: harry. cuppens@med.kuleuven.ac.be

Received for publication 14 May 1997 and accepted in revised form 19 November 1997.

J. Clin. Invest.

(C) The American Society for Clinical Investigation, Inc. 0021-9738/98/01/0487/10 \$2.00

Volume 101, Number 2, January 1998, 487-496

http://www.jci.org membrane conductance regulator $\bullet$ cystic fibrosis $\bullet$ congenital bilateral absence of the vas deferens $\bullet$ splicing $\bullet$ haplotype background

\section{Introduction}

Mutations in the cystic fibrosis transmembrane conductance regulator $(C F T R)^{1}$ gene (1), which encodes a chloride channel (2), cause cystic fibrosis (CF; 3-6). The disease phenotype of $\mathrm{CF}$ patients is quite variable, however, going from severe pulmonary disease with pancreatic insufficiency to severe pulmonary disease with pancreatic sufficiency (PS), to atypical CF (i.e., CF-like pulmonary disease with normal sweat test). CFTR mutations, however, are also involved in diseases that only share part of the symptoms observed in CF patients, such as congenital bilateral absence of the vas deferens (CBAVD; 7-10). Finally, CFTR mutations have been found at significantly higher than expected frequencies in patients with disseminated bronchiectasis (11) and allergic bronchopulmonary aspergillosis (12). CFTR mutations, therefore, appear to be associated with a broad spectrum of clinical phenotypes.

Patients that present with a milder phenotype usually are heterozygotes for a mild mutation on one CFTR allele and a severe one on the second allele, or may even carry mild mutations on both CFTR genes. Milder mutations, such as the $3849+10 \mathrm{kbC} \rightarrow \mathrm{T}$ mutation (13), could be located in regions recognized by the splicing machinery when some normal splicing still occurs. Mutations that affect the conductivity properties of CFTR, such as R117H, R334W, and R347P, are other examples of mild mutations $(6,14)$. Some mutations can be responsible for different phenotypes. For example, the R117H mutation is found in PS-CF patients as well as in CBAVD patients (15), and the difference in phenotypic expression has been explained by the polymorphic Tn locus in front of exon 9 . Three alleles (T5, T7, and T9) can be found at this polymorphic locus (16). These alleles determine the efficiency by which the intron 8 splice acceptor site is used $(16,17)$. The efficiency will decrease when a shorter stretch of thymidine residues is found. A higher proportion of CFTR transcripts that lack exon 9 sequences, which encode part of the functionally important first nucleotide-binding domain, will therefore be found when a shorter stretch of thymidine residues is present $(16,17)$. Such transcripts are known to be translated in CFTR proteins that do not mature, and will therefore not result in apical chloride channel activity $(18,19)$. If a R117H CFTR gene harbors a T5

1. Abbreviations used in this paper: CBAVD, congenital bilateral absence of the vas deferens; CF, cystic fibrosis; CFTR, cystic fibrosis transmembrane conductance regulator; PKA, protein kinase A; PS, pancreatic sufficiency. 
allele, the mutant gene will be responsible for CF (15). A R117H mutant CFTR gene that harbors a T7 allele can either result in CF or CBAVD (15).

However, the T5 allele alone can be responsible for disease, such as CBAVD. Indeed, compared with control individuals, the T5 allele is found at an increased frequency in CBAVD patients (8-10). A considerable number of CBAVD patients are compound heterozygotes for a true CFTR disease mutation and a T5 CFTR gene (8-10). Some CBAVD patients are even homozygous for two T5 CFTR genes (8). However, the number of male individuals that carry one of the latter two genotypes is much higher than the frequency of CBAVD in the general population (10). Among these are fathers of the patients, who are clearly not affected but harbor Tn CFTR genotypes that are also observed in CBAVD individuals $(8,10$, 20). The T5 allele has therefore been classified as a CBAVD disease mutation with partial penetrance (10). The fact that T5 can either result in disease or no disease makes genetic counseling of these individuals complex.

Besides the polymorphic Tn locus, more than 120 polymorphic loci have been described in the CFTR gene $(4,5)$. Some of the alleles found at polymorphic loci located in exons coding for the first nucleotide-binding domain, as well as in their exon/intron splice junctions, reach high frequencies in the general population. These include polymorphisms found at the (TG)m and M470V loci $(9,20)$. Although a particular allele may not by itself have deleterious consequences, we hypothesized that the combination of particular alleles at several polymorphic loci might result in less functional, or even insufficient CFTR protein. Here we show that particular alleles at these polymorphic loci do indeed affect the final quantity and/or quality of CFTR. Moreover, the combination of particular alleles are found to explain the partial penetrance of T5 as a disease mutation. For these reasons we would name these genes polyvariant mutant $C F T R$ genes.

\section{Methods}

Studied samples. Nasal biopsies were obtained from patients suffering from chronic nasal obstruction or sinusitis. These patients did not suffer from disseminated bronchiectasis or chronic obstructive pulmonary disease (COPD). T5 CFTR genes were derived from CBAVD, $\mathrm{CF}$ patients, parents of $\mathrm{CF}$ patients, and random fertile people. The majority of CBAVD patients have been described previously (9). The PS-CF patient was the only patient of the more than $100 \mathrm{CF}$ patients that were completely sequenced over the complete coding region and the exon/intron junctions of $C F T R$ that was found to be a compound heterozygote for the T5 allele and a severe $C F T R$ mutation $(\triangle \mathrm{F} 508)$. Given the low frequency of the T5 allele (0.06) in the general population (20), only a limited number of T5 CFTR genes derived from random fertile people could be studied.

Genomic analysis. The $\Delta \mathrm{I} 507, \Delta \mathrm{F} 508,1717-1 \mathrm{G} \rightarrow \mathrm{A}, \mathrm{G} 542 \mathrm{X}$, G551D, R553X, W1282X, and N1303K mutations were screened by means of the INNO-LiPA CF2 assay (Innogenetics, Zwijndrecht, Belgium) according to protocols provided by the manufacturer. The $3849+10 \mathrm{kbC} \rightarrow \mathrm{T}$ mutation was screened as described by Highsmith et al. (13). Sequencing of exons 8-10 and their exon/intron junctions was performed as previously described (21), which allowed both screening for mutations and genotyping at the (TG)m and Tn loci. The (TG)m locus immediately precedes the Tn locus, both of which are located at the end of intron 8 . The alleles at these loci were designated according to the number of repeats. Amplification across the M470V locus was also performed as previously described (21). The alleles present at these loci, which were designated according to the amino acid found, were determined by means of $\mathrm{HphI}$ restriction enzyme analysis. The M470V locus is located in exon 10 and encodes part of the first nucleotide-binding domain. The alleles found at these polymorphic loci are rather frequent in the general population $(9,20)$.

Determination of CFTR haplotypes. The haplotypes, when possible, were determined by segregation analysis. If no relatives were available and the individuals were compound heterozygotes for a true CF mutant CFTR gene, the haplotypes could be deduced according to previous haplotype analysis of known CF mutations (20). Indeed, a particular CF mutation is almost always found to be associated with one particular allele at associated polymorphic loci (20).

Qualitative and quantitative CFTR transcript analysis. Nasal epithelial cells were cultured for one or two passages as previously described (22). Total RNA was extracted from the cultured nasal epithelial cells with the TRIzol ${ }^{\mathrm{TM}}$ reagent and converted into cDNA with M-MLV reverse transcriptase, using $\operatorname{pd}(\mathrm{T})_{12-18}$ primers (Pharmacia Biotech Inc., Piscataway, NJ) according to protocols provided by the manufacturer (Life Technologies). Qualitative and quantitative CFTR transcript analysis was performed as previously described (23). For samples heterozygous for the alleles at the M470V locus, PCR products were also digested with $\mathrm{HphI}$ and analyzed by qualitative and quantitative means. The proportion of each type of transcript derived from each allele was calculated as follows: the proportion of M470 exon $9+$ transcripts is equal to the proportion contributed by the 357-bp signal in the digested sample; the proportion of V470 exon $9+$ transcripts is equal to the proportion contributed by the 559-bp signal in the undigested sample minus the proportion of M470 exon 9+ transcripts calculated above; the proportion of M470 exon 9- transcripts is equal to the proportion contributed by the 376-bp signal in the digested sample; and the proportion of V470 exon 9- transcripts is equal to the proportion contributed by the 376-bp signal in the undigested sample minus the proportion of M470 exon 9- transcripts calculated above.

Plasmid constructions and transfections. A Kpn I Xho I CFTR cDNA fragment was isolated from the prokaryotic vector pTG5960 (Transgene, Strasbourg, France), which contains a CFTR cDNA construct in which the cryptic bacterial promoter (24) has been inactivated $(\mathrm{T} \rightarrow \mathrm{C}$ at $930, \mathrm{~A} \rightarrow \mathrm{G}$ at $933, \mathrm{~T} \rightarrow \mathrm{C}$ at 936$)$ and ligated into the pcDNA3 expression vector (Invitrogen Corp., San Diego, CA). Subsequently, the construct was digested with Kpn I and Eco RV in order to remove a potential ATG start codon that was derived from the polycloning site of pTG5960. The termini were subsequently bluntended, and the construct was religated. Sequencing the complete CFTR coding region of this construct did not reveal any differences apart from V470 and silent mutations introduced for inactivation of the cryptic bacterial promoter from the CFTR amino acid sequence (1). From this construct, a M470 CFTR cDNA/pcDNA3 construct was made by means of the Transformer ${ }^{\mathrm{TM}}$ Site-directed Mutagenesis Kit (Clontech, Palo Alto, CA) according to protocols provided by the manufacturer (mutagenesis primer: 5'-TTC ACT TCT AAT GAT GAT TAT GGG A-3'; selection primer: 5'-CTC TGG GGT CCG GAA TGA CCG AC-3', which will destroy a BstBI site). The complete $C F T R$ coding region of this construct was also verified by sequencing. Only the mutagenesis event was observed; no other mutations had been introduced. Both constructs were then transiently transfected in COS-1 cells or stably transfected in CHO-K1 cells according to protocols previously described (25).

Pulse-chase experiments. Transfected cells were preincubated for $30 \mathrm{~min}$ in methionine- and cysteine-free RPMI 1640 medium, supplemented with L-leucine, L-arginine, glucose, L-glutamine, I-inositol (Life Technologies), and $10 \mathrm{mM}$ Hepes for $30 \mathrm{~min}$ at $37^{\circ} \mathrm{C}$. The transfected cells were labeled in the same medium containing $100 \mu \mathrm{Ci} / \mathrm{ml}$ $\left[{ }^{35} \mathrm{~S}\right]$ methionine and $\left[{ }^{35} \mathrm{~S}\right]$ cysteine (ICN Pharmaceuticals Inc., Costa Mesa, CA) during a pulse of $15 \mathrm{~min}$, and then chased for different time periods at $37^{\circ} \mathrm{C}$. For chasing, the labeling medium was replaced with DME-F12 medium (Life Technologies) supplemented with $10 \%$ FBS (HyClone, Logan, UT). The cell monolayers were scraped in icecold Tris- $\mathrm{NaCl}$ buffer ( $20 \mathrm{mM}$ Tris- $\mathrm{HCl}, 150 \mathrm{mM} \mathrm{NaCl}$; $\mathrm{pH}$ 7.4) sup- 
plemented with protease inhibitors (antipain, chymostatin, leupeptin, and pepstatin A at $0.5 \mu \mathrm{g} / \mathrm{ml}, 0.5 \mathrm{mM}$ phenylmethylsulfonylfluoride, $10 \mu \mathrm{g} / \mathrm{ml}$ soybean trypsin inhibitor). The cells were solubilized at $4^{\circ} \mathrm{C}$ in $750 \mu$ IPPA buffer (Tris- $\mathrm{NaCl}$ buffer, $1 \% \mathrm{Na}^{+}$-desoxycholate, $1 \%$ Triton X-100, 0.1\% SDS; pH 7.4), supplemented with protease inhibitors, and sonicated briefly. After centrifugation at $4^{\circ} \mathrm{C}$, the supernatant was precleared on protein A Sepharose CL-4B beads (Pharmacia Biotech Inc.) at $4^{\circ} \mathrm{C}$. The precleared supernatant was then incubated at $4^{\circ} \mathrm{C}$ with $1.5 \mu \mathrm{g} \mathrm{COOH}$ terminus-specific monoclonal mouse antihuman CFTR antibody (Genzyme Corp., Boston, MA) or HCF703 monoclonal antibody directed against the R domain (26). The immune complexes were precipitated with protein A Sepharose CL-4B beads at $4{ }^{\circ} \mathrm{C}$ followed by four washes in IPPA buffer supplemented with protease inhibitors. Immunoprecipitated proteins were eluted and denatured in sample buffer (13 mM Tris- $\mathrm{HCl}, 3.25 \%$ SDS, $1 \% \beta$-mercaptoethanol, $25 \%$ glycerol; $\mathrm{pH} 6.8$ ) for $15 \mathrm{~min}$ at room temperature. The samples were analyzed by electrophoresis on a 4-12\% Tris-glycine PAGE gel (Novex, San Diego, CA) and autoradiography.

Whole-cell and single-channel recordings. Transfected cells selected for G418 resistance were seeded on glass coverslips and cultured overnight in DME-F12 medium supplemented with $10 \%$ FBS. For whole-cell and single-channel measurements, a conventional patch clamp device was used (EPC-7 amplifier; List, Darmstadt, Germany; pipette resistance 5-10 $\mathrm{M} \Omega$; data acquisition by Clampex version 5.5.1 software package; Axon Instruments Inc., Forster City, CA). Whole-cell recordings were performed at room temperature (sampling rate $1 \mathrm{kHz}$, filter setting $200 \mathrm{~Hz}$ ). Two second voltage ramps applied every $15 \mathrm{~s}$ from -100 to $+100 \mathrm{mV}$ were used for monitoring of I-V relationships (holding potential $0 \mathrm{mV}$ ). Currents were analyzed at $+100 \mathrm{mV}$. In addition, voltage step protocols were used (duration $1 \mathrm{~s},-100-+100 \mathrm{mV}$, increment $20 \mathrm{mV}$, holding potential $0 \mathrm{mV}$ ). Single-channel recordings were performed at $35^{\circ} \mathrm{C}$ and were analyzed by means of the ASCD-software program (27). Currents were digitized at $1 \mathrm{kHz}$ and filtered at $500 \mathrm{~Hz}$ (holding potential of $-60 \mathrm{mV}$ ).

For whole-cell recordings, the pipette (internal solution) contained (in $\mathrm{mM}$ ): $100 \mathrm{Cs}^{+}$- aspartate, $20 \mathrm{CsCl}, 20$ tetraethylammonium chloride, 5 Hepes, 4 EGTA, 4 Mg-ATP; $\mathrm{pH}$ 7.2. The bath solution contained (in mM): $150 \mathrm{NaCl}, 10$ glucose, 10 Hepes, $5.9 \mathrm{KCl}, 1.2$ $\mathrm{MgCl}_{2}, 1 \mathrm{CaCl}_{2} ; \mathrm{pH}$ 7.4. To block $\mathrm{K}^{+}$currents, $\mathrm{KCl}$ was substituted by $\mathrm{CsCl}$ before activation of the $\mathrm{Cl}^{-}$currents. CFTR-mediated conductance was activated by a phosphorylation cocktail containing $1 \mu \mathrm{M}$ forskolin and $10 \mu \mathrm{M}$ IBMX (Sigma Chemical Co, St. Louis, MO). $50 \mu \mathrm{M}$ glybenclamide (Sigma Chemical Co.) was used for inhibition of channel activity.

For single-channel recordings, the pipette solution contained (in $\mathrm{mM}$ ): $140 \mathrm{~N}$-methyl-D-glucamine, 100 aspartate acid, 10 Hepes, 2 $\mathrm{MgCl}_{2}, 1 \mathrm{CaCl}_{2}, 35 \mathrm{HCl} ; \mathrm{pH}$ 7.3. The bath solution contained (in $\mathrm{mM}$ ): $140 \mathrm{~N}$-methyl-D-glucamine chloride, $10 \mathrm{NaF}, 10 \mathrm{Hepes}, 5 \mathrm{CsCl}$, $2 \mathrm{MgCl}_{2}, 1 \mathrm{Mg}$-ATP, 1 EGTA; pH 7.2. The channels were activated through addition of $75 \mathrm{nM}$ protein kinase A (PKA; Promega Corp, Madison, WI).

Oocytes and RNA injection. Female toads (Xenopus laevis) were anaesthetized by immersion in ice water containing $2 \mathrm{~g} /$ liter 3 -amino benzoic acid ethyl ester (Sigma Chemical Co.), and oocytes were removed via a small abdominal incision. The follicular membranes were removed and incubated for $1 \mathrm{~h}$ in a calcium-free solution containing 2 $\mathrm{mg} / \mathrm{ml}$ collagenase A (Boehringer Mannheim Biochemicals, Indianapolis, IN). CFTR transcripts were in vitro-transcribed from the $C F T R$ cDNA/pcDNA3 constructs using the T7 RiboMAX ${ }^{\mathrm{TM}}$ largescale RNA production kit (Promega Corp.) according to the protocol provided by the manufacturer. Defolliculated oocytes were injected with $50 \mathrm{nl}$ RNA $(5 \mu \mathrm{g} / \mu \mathrm{l})$.

Two-electrode voltage-clamp assays. Oocytes injected 2-3 d previously were voltage-clamped with a two-electrode technique and continuously perfused with ND96 solution $(96 \mathrm{mM} \mathrm{NaCl}, 5 \mathrm{mM}$ Hepes, $2 \mathrm{mM} \mathrm{KCl}, 1.8 \mathrm{mM} \mathrm{CaCl}_{2}, 1 \mathrm{mM} \mathrm{MgCl}$; pH 7.4, $100 \mu \mathrm{M}$ niflumic acid; Sigma Chemical Co.) to block endogenous $\mathrm{Ca}^{2+}$-activated $\mathrm{Cl}^{-}$ currents. CFTR-mediated currents were activated by a cocktail containing $10 \mu \mathrm{M}$ forskolin and $1 \mathrm{mM}$ IBMX. Membrane currents in uninjected, water-injected or mock-injected oocytes were unresponsive.

Table I. Proportion of Exon9-CFTR Transcripts in Cultured Nasal Epithelial Cells

\begin{tabular}{|c|c|c|c|c|c|}
\hline Genotype & Haplotype & $\begin{array}{c}\text { Sample } \\
\text { no. }\end{array}$ & $\begin{array}{l}\text { Proportion } \\
\text { exon } 9- \\
\text { transcripts }\end{array}$ & $n$ & $\begin{array}{c}\text { Proportion exon 9- } \\
\text { transcripts/ } \\
\text { haplotype }\end{array}$ \\
\hline I & $\begin{array}{l}\text { D: TG10/T9/M470 } \\
\text { B: TG10/T7/M470 }\end{array}$ & 1 & $0.03 \pm 0.01$ & 19 & \\
\hline II & D: TG10/T9/M470 & 2 & $0.11 \pm 0.01$ & 13 & D: $0.02-A: 0.22$ \\
\hline III & $\begin{array}{l}\text { B: TG10/T7/M470 } \\
\text { B: TG10/T7/M470 }\end{array}$ & 4 & $0.05 \pm 0.01$ & 9 & \\
\hline IV & $\begin{array}{l}\text { B: TG10/T7/M470 } \\
\text { A: TG11/T7/V470 }\end{array}$ & $\begin{array}{l}5 \\
6 \\
7 \\
8\end{array}$ & $\begin{array}{l}0.08 \pm 0.01 \\
0.09 \pm 0.01 \\
0.10 \pm 0.01 \\
0.10 \pm 0.01\end{array}$ & $\begin{array}{l}15 \\
17 \\
15 \\
12\end{array}$ & $\begin{array}{l}\text { B: } 0.04-A: 0.14 \\
\text { B: } 0.06-A: 0.12 \\
\text { B: } 0.07-A: 0.13 \\
\text { B: } 0.06-A: 0.15\end{array}$ \\
\hline V & $\begin{array}{l}\text { A: TG11/T7/V470 } \\
\text { A: TG11/T7/V470 }\end{array}$ & $\begin{array}{r}9 \\
10 \\
11 \\
12 \\
13 \\
14 \\
15 \\
16 \\
17 \\
18 \\
19 \\
20 \\
21 \\
22\end{array}$ & $\begin{array}{l}0.12 \pm 0.01 \\
0.13 \pm 0.01 \\
0.14 \pm 0.02 \\
0.16 \pm 0.01 \\
0.17 \pm 0.01 \\
0.12 \pm 0.01 \\
0.15 \pm 0.01 \\
0.12 \pm 0.01 \\
0.16 \pm 0.01 \\
0.14 \pm 0.01 \\
0.12 \pm 0.01 \\
0.13 \pm 0.01 \\
0.16 \pm 0.01 \\
0.12 \pm 0.01\end{array}$ & $\begin{array}{r}14 \\
11 \\
9 \\
13 \\
10 \\
13 \\
15 \\
10 \\
12 \\
15 \\
12 \\
13 \\
10 \\
8\end{array}$ & \\
\hline VI & $\begin{array}{l}\text { A: TG11/T7/V470 } \\
\text { C: TG12/T7/M470 }\end{array}$ & $\begin{array}{l}23 \\
24 \\
25\end{array}$ & $\begin{array}{l}0.21 \pm 0.01 \\
0.20 \pm 0.01 \\
0.23 \pm 0.02\end{array}$ & $\begin{array}{l}15 \\
14 \\
13\end{array}$ & $\begin{array}{l}\text { C: } 0.29-A: 0.08 \\
\text { C: } 0.30-A: 0.05 \\
\text { C: } 0.32-A: 0.03\end{array}$ \\
\hline VII & $\begin{array}{l}\text { B: TG10/T7/M470 } \\
\text { E: TG12/T5/V470 }\end{array}$ & 26 & $0.46 \pm 0.01$ & 9 & B: $0.10-E: 0.72$ \\
\hline
\end{tabular}

Haplotypes (A-E) were built up by alleles found at the (TG)m, Tn, and M470V loci, respectively. For each type of transcript, the average proportion and the standard error of the mean was calculated. Only the quantitative data of exon 9- transcripts are given. For individuals heterozygous at the M470V locus, the proportion of exon 9- transcripts was calculated for the transcripts derived from each CFTR gene individually (haplotypes A-E are indicated). The total number of all independent measurements is given $(n)$. This number comprises the number of RNA extractions (twice for samples 1, 6, 7 and 22; once for the remainder), the number of independent cDNA synthesis reactions from each of these RNA extractions (1-3), the number of independent PCR reactions from each of the cDNA synthesis reactions (3-6), and replicate loadings of the latter samples $(1,2)$. A further control was the use of duplicate PCR reactions, one being performed for two additional PCR cycles. The latter control was used to check if the different fragments were equally well amplified. Indeed, in the saturation phase of the PCR, smaller fragments could be more efficiently amplified than larger fragments. For each sample, the qualitative and quantitative measurements for the duplicate PCR reactions were not significantly different from each other showing that the smaller fragments were not more efficiently amplified. 


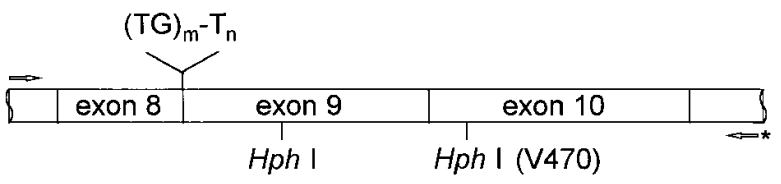

A. exon9+ transcript

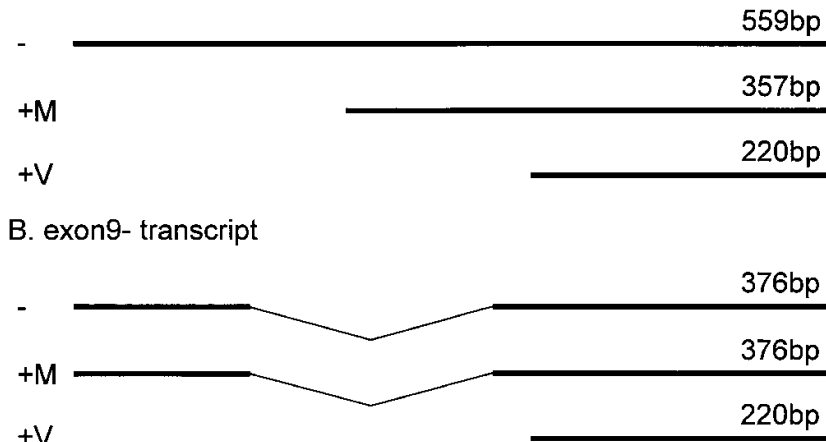

Figure 1. Schematic representation of PCR products derived from $C F T R$ transcripts, used for qualitative and quantitative analysis. The primer denoted with an asterisk carries a FITC moiety. Polymorphic sites are indicated. The ones shown (top) are located in intronic regions. M470V is located in the coding region. The HphI site in exon 10 is only present if the $\mathrm{V}$ allele is present. $(A)$ PCR fragment derived from the exon $9+$ transcript; $(B)$ PCR fragment derived from the exon 9- transcript. -, FITC-labeled M470 or V470 fragment obtained after amplification; +M, FITC-labeled M470 fragment obtained after $H p h$ I digestion; + V, FITC-labeled V470 fragment obtained after $H p h \mathrm{I}$ digestion.

\section{Results}

Characterization of CFTR genes. Cultured epithelial cells of nasal biopsies obtained from 26 individuals were tested for the presence of one of the eight most common CFTR mutations, representing $85 \%$ of all CF mutations in our population. No mutation could be identified. The mild mutation, $3849+10 \mathrm{kbC} \rightarrow \mathrm{T}$ was also not found in any of these samples. Sequencing of exons 8-10 and their exon/intron junctions did not reveal any disease mutation apart from the polymorphic sites described below. Next, the alleles present at the polymorphic (TG)m, Tn, and M470V loci were determined, and the haplotypes composed of the different alleles of these polymorphic loci were constructed (Table I). The different haplotypes are given in Table I. The five haplotypes thus observed could be combined in seven different genotypes.

CFTR transcript analysis. Since the nasal epithelium is in direct contact with the environment, expression of CFTR might be influenced by exogenous factors such as infections. Indeed, it has been shown that CFTR expression is different in injured and repairing tissue compared with the same tissue under normal physiological conditions (28). Culture of the nasal epithelial cells will remove infection and other environmental influences so that the cells can be studied under comparable conditions, and so that differences in the nature of the transcripts found during analysis could be completely attributed to the genetic constitution of the cells. Moreover, sufficient material could be obtained from these cultures to perform replicate measurements to test the findings for their significance. For these reasons, only cultured nasal epithelial cells derived from the individuals described in Table I were studied. Nevertheless, for samples 3,4 , and 21 , we have previously shown that the qualitative and quantitative nature of the transcripts did not differ if they were derived from either fresh biopsies or from cultured cells.

Reverse transcription PCR was performed across sequences coding for the first nucleotide-binding domain such that alternative splicing of exon 9 could be studied (Fig. 1). This region also harbors the $\mathrm{M} 470 \mathrm{~V}$ locus. The $\mathrm{M}$ and $\mathrm{V}$ alleles can be discriminated by restriction enzyme analysis, which allows one to discriminate between the two types of transcripts derived from each $C F T R$ gene in individuals heterozygous at the M470V locus (Fig. 1). The results are summarized in Table I.

In all samples studied, alternative splicing of exon 9 was observed. In agreement with previous studies (17), the amount of alternatively spliced transcripts increased when a shorter stretch of thymidine residues was present at the Tn locus. Moreover, we found that the number of TG repeats also correlated with the proportion of exon 9- transcripts. Analysis of genotypes III-VI homozygous for the $\mathrm{T} 7$ allele revealed that increasing proportions of exon 9- transcripts were observed

Table II. Nucleotide Sequences of Intron 8 Splice Branch/Acceptor Sites of the Different CFTR Haplotypes' Buildup of Alleles at the (TG)m and Tn loci

(TG) 11-T9:

(TG) 10-T9:

(TG) 9-T9:

(TG) 12-T7:

(TG) 11-T7:

(TG) 10-T7:

(TG) 13-T5:

(TG) 12-T5:

(TG) 11-T5:

Consensus:

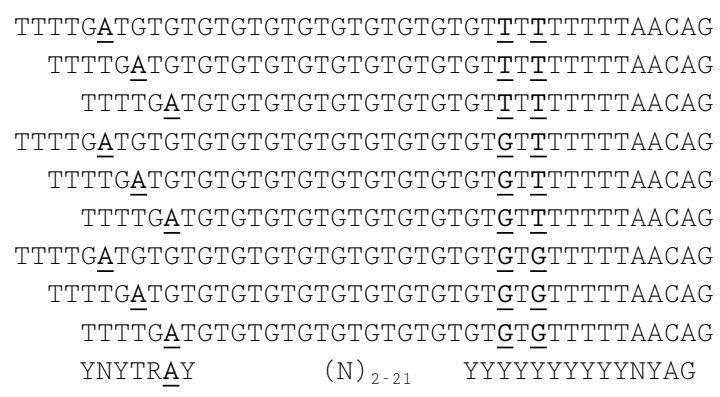

The consensus splice branch/acceptor site (17) is also given. Nucleotides at the Tn locus, which are part of the splice acceptor consensus sequence (17) that vary between the different haplotypes, are underlined. The branchpoint A nucleotide of the lariat formed during the splicing reaction is given in bold and is underlined. The TG repeats encode part of the splice branch site consensus sequence (17). sb, splice branch site consensus sequence; sa, splice acceptor site consensus sequence. 
when a longer stretch of TG repeats was found independent of the allele present at the Tn locus. ANOVA showed that the mean proportion of exon 9- transcripts derived from haplotypes A-C were significantly different from each other $(P<$ $\left.10^{-6}\right)$. Subsequent post-hoc pairwise comparison tests according to Bonferroni showed that the means for all tested haplotypes were significantly different from each other $\left(P<10^{-6}\right)$. The Spearman rank correlation coefficient was 0.67 , and the Pearson correlation coefficient was $0.84\left(P<10^{-9}\right)$ by ranking for the number of TG repeats. On a $\mathrm{T} 7$ background, the (TG)11 allele increased the proportion of exon 9- transcripts 2.8-fold compared with a (TG)10 allele, and even sixfold in the presence of a (TG) 12 allele. It should be noted that these haplotypes also differed for alleles at the M470V locus. The different alleles at the Tn locus affect the efficiency by which the splice acceptor consensus sequence is recognized, while the different alleles at the (TG)m locus place the branchpoint A nucleotide in a less favorable position for splicing (Table II).

Another interesting observation was that the proportion of exon9- transcripts derived from a haplotype A gene varied depending on the haplotype found in trans: $0.18 \pm 0.06(n=2)$ for haplotype $\mathrm{D} ; 0.14 \pm 0.01(n=4)$ for haplotype $\mathrm{B}$; and $0.05 \pm 0.02(n=3)$ when haplotype $\mathrm{C}$ was found in trans (Table I). ANOVA showed that the mean proportion of exon 9transcripts from haplotype $\mathrm{A}$ found in these three groups were significantly different $(P<0.02)$. Subsequent post-hoc pairwise comparison tests according to Bonferroni showed that the mean proportion of haplotype A exon 9- transcripts for genotype A/C was significantly different from the ones found for the A/B $(P<0.05)$ and A/D $(P<0.02)$ genotypes. The Pearson correlation coefficient was $-0.87(P<0.01)$.

It can thus be concluded that another locus than the Tn locus alone determines the extent to which exon 9- transcripts are found.

Maturation of M470 and V470 CFTR. In contrast with the polymorphic loci (TG)m and Tn, the M470V locus is polymorphic at the amino acid level. Therefore, the kinetics of maturation and degradation of these two variant CFTR proteins were studied. M470 or V470 CFTR was transiently expressed in COS cells. After metabolic labeling of the transfected cells and subsequent chases during different time periods, the cells were lysed and CFTR was immunoprecipitated with a monoclonal antibody directed against the COOH-terminal part of CFTR (Fig. 2 A). Both M470 and V470 CFTR did mature up to the complex-glycosylated CFTR form (C-form). Since both alleles at the M470V locus are frequent in the general population and both are therefore found in individuals not affected by $\mathrm{CF}$ or its related diseases, this finding was not unexpected. As expected, both for M470 an V470 CFTR, a substantial proportion of the primary translation and core-glycosylated CFTR products was degraded $(24,29)$. However, M470 CFTR proteins matured more slowly than V470 CFTR. As shown in Fig. $2 A$, small amounts of complex-glycosylated V470 CFTR protein were already found after a chase of $45 \mathrm{~min}$, and most of the complex-glycosylated V470 CFTR protein appeared after a chase of $2 \mathrm{~h}$ and $30 \mathrm{~min}$. In contrast, most of the complex-glycosylated M470 CFTR protein appeared only after a chase of $3 \mathrm{~h}$ and $30 \mathrm{~min}$. This difference in kinetics did not depend on the cell type used for transfection since it was also observed in stable transfected CHO cells (Fig. 2 B). Moreover, similar observations were made when another monoclonal antibody directed against the $\mathrm{R}$ domain was used for immunoprecipitation of CFTR (Fig. $2 C$ ). Within each experiment $(n=6)$, relative differences in maturation were systematically observed between M470 and V470 CFTR.

A potential interesting observation was that before reaching full glycosylation, i.e., after $1 \mathrm{~h}$ and $30 \mathrm{~min}$ of chase for V470 CFTR, and $1 \mathrm{~h}$ and $30 \mathrm{~min}$ and $2 \mathrm{~h}$ and $30 \mathrm{~min}$ for M470 CFTR, hardly any CFTR protein could be precipitated from COS cells (Fig. $2 A$ ). The time period during which the majority of CFTR could not be detected was thus increased for M470 when compared with V470 CFTR proteins. This finding could not be studied in $\mathrm{CHO}$ cells since the primary translation and core-glycosylated CFTR products are not observed in this cell system. A possible explanation for the poor immunoprecipitation of CFTR could be that during these time periods CFTR adopted a configuration, or bound to another protein such that its $\mathrm{COOH}$-terminal epitope was not accessible to this antibody. Taken together, these findings suggest that the allele present at the polymorphic locus M470V affects biogenesis of CFTR.

Electrophysiological characterization of M470 and V470 CFTR. Permeation and gating properties of M470 and V470 CFTR proteins, transiently expressed in COS cells, were analyzed by the patch clamp method in whole cell and single-channel configurations. In the whole cell configuration, expression of both V470 and M470 CFTR did result in the appearance of a current after stimulation of the cells with a phosphorylation cocktail. Nearly linear I-V relationships were obtained for the cAMP-activated currents (Fig. $3 A$ ). The current carried by
A

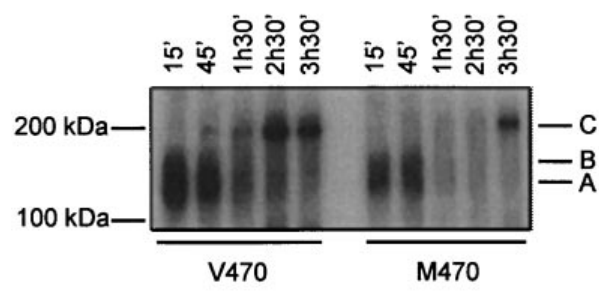

B

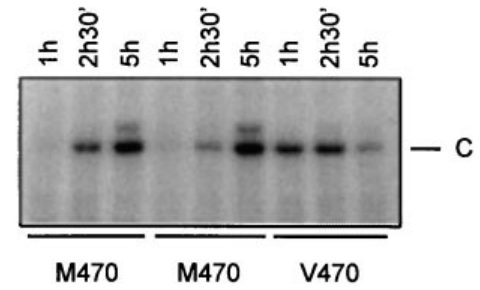

C

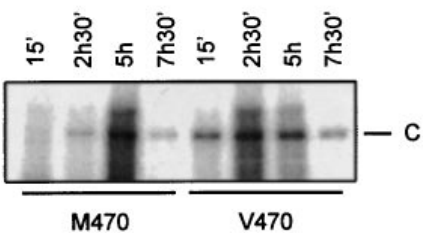

Figure 2. Analysis of the biogenesis and degradation of M470 and V470 CFTR in transfected cells. $(A)$ COS cells or $(B, C)$ CHO cells transfected with either M470 or V470 CFTR were metabolically labeled and chased for the indicated times. The cells were then lysed, and CFTR was immunoprecipitated with monoclonal antibodies either directed to the $\mathrm{COOH}$ terminus (A, B) or the R domain (C) and analyzed by PAGE and autoradiography. Two M470 CHO clones are shown in $B$. The positions of the molecular weight markers and the primary translation (A-form), core-glycosylated (B-form), and complex-glycosylated (C-form) CFTR products are indicated. 
B

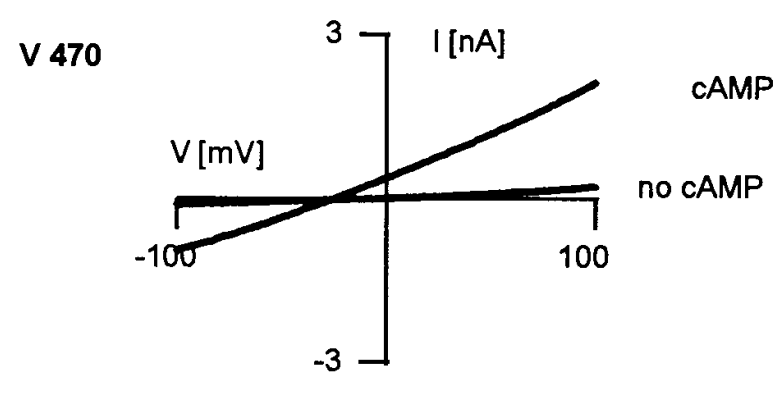

M 470
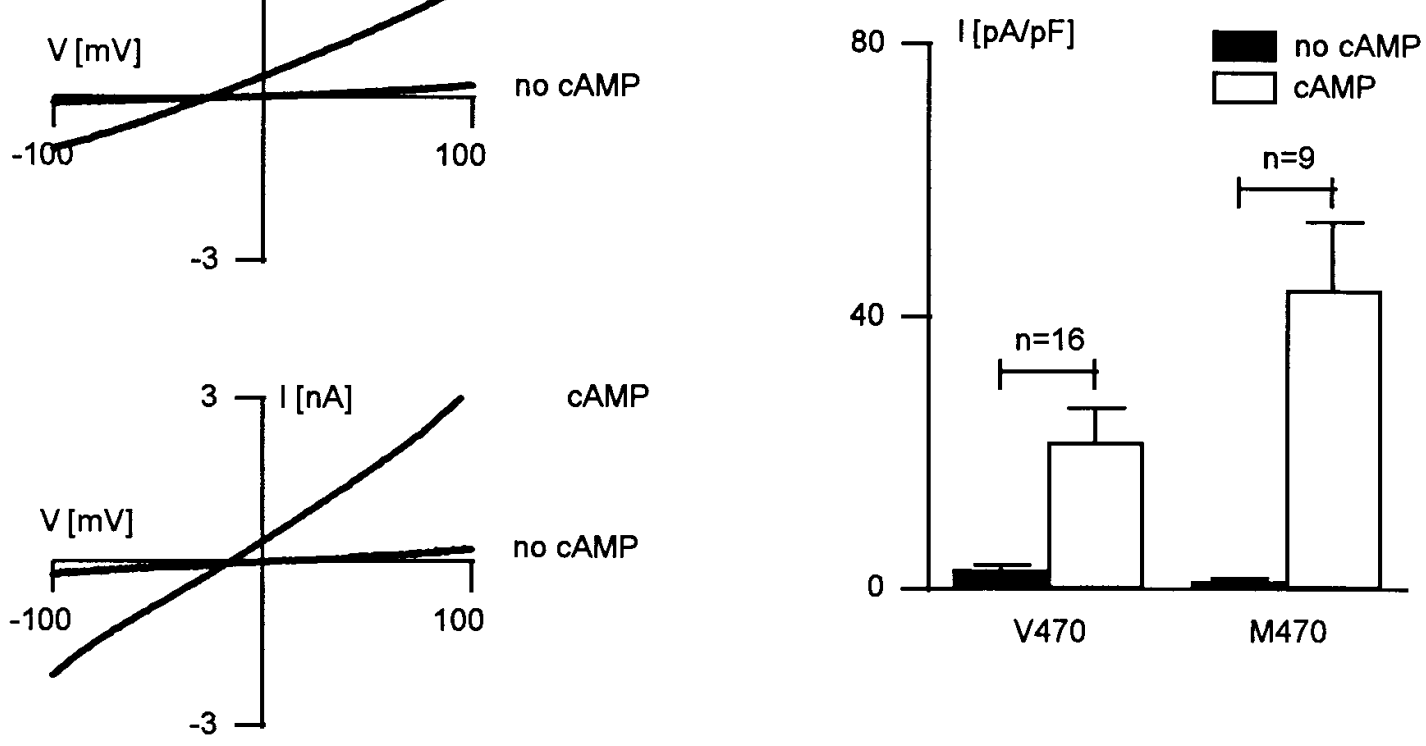

C
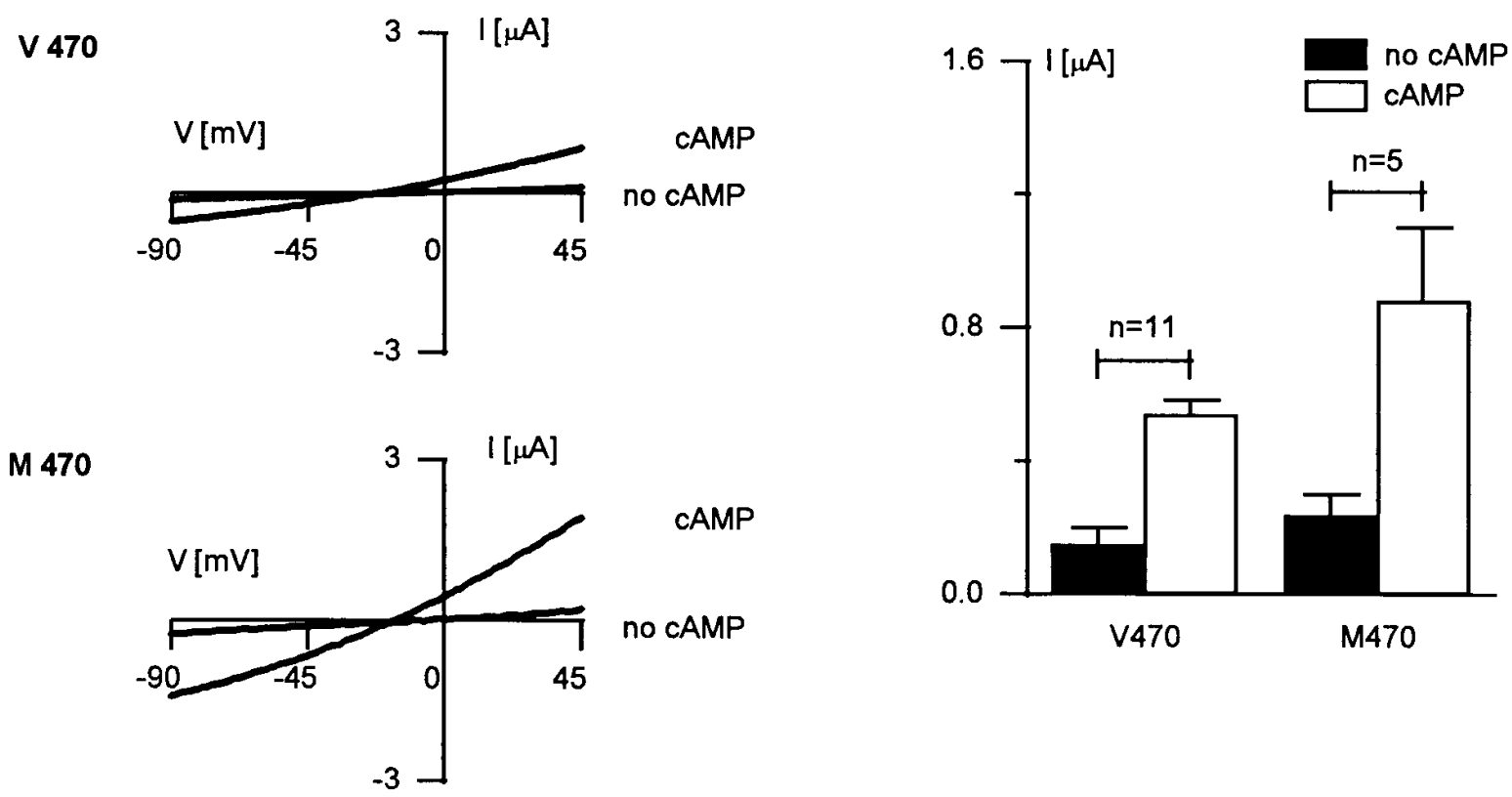

Figure 3. Whole-cell currents of cells that transiently expressed M470 or V470 CFTR. (A) Current-voltage (I-V) relationships obtained from whole-cell currents of COS cells that transiently expressed V470 or M470 under basal conditions and after addition of cAMP activation cocktail to the bath solution. I-V relationships were obtained by $2 \mathrm{~s}$ voltage ramps. (B) Comparison of the current densities for COS cells transfected with V470 or M470 CFTR (with or without cAMP activation) at $+100 \mathrm{mV}$. (C) I-V relationships of $\mathrm{Cl}^{-}$currents obtained from oocytes injected with RNA for V470 or M470 CFTR (with or without cAMP stimulation). (D) Comparison of currents in RNA-injected oocytes with V470 or M470 CFTR constructs (with or without cAMP activation). Currents were measured from the ramp protocols at $-90 \mathrm{mV}$. 
A

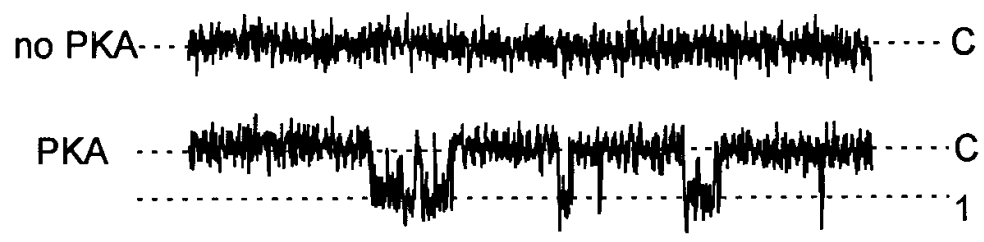

M470

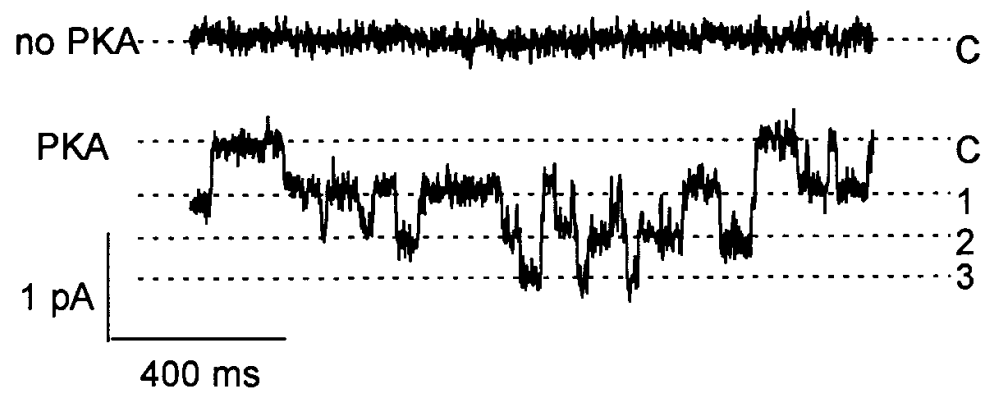

B

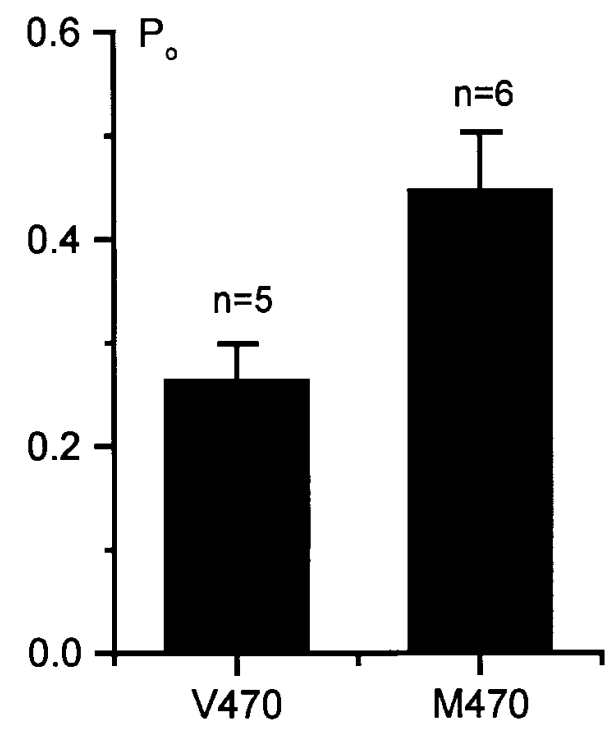

Figure 4. Activation of chloride channels in excised, inside-out patches from COS cells that transiently expressed M470 or V470 CFTR. (A) Representative current traces of single-channel recordings of V470 or M470 CFTR, with or without addition of PKA from the internal site of the membrane patch. C marks the closed state of the channel. 1-3 indicate open channel events. $(B)$ Comparison of the probability of the channel being open $\left(P_{o}\right)$, pooled from all cells. $P_{o}$ of V470 and M470 CFTR channels was measured at $-60 \mathrm{mV}$ after application of PKA. $P_{o}$ was calculated either from the probability density functions (amplitude histograms) or from the averaged mean currents divided by the single-channel current. The number of channels was estimated from the maximal number of overlapping opening events. This may even lead to an overestimation of $\mathrm{P}_{\mathrm{o}}$ given in the pooled data for V470 CFTR channels that open with a lower probability than M470 CFTR.

V470 CFTR channels was characterized by a reversal potential of $-24 \mathrm{mV}$, which is close to the theoretical chloride equilibrium potential $\left(\mathrm{E}_{\mathrm{Cl}}=-33 \mathrm{mV}\right.$, Fig. $\left.3 \mathrm{~A}\right)$. Glybenclamide, in a concentration of $50 \mu \mathrm{M}$, inhibited this current by $78 \pm 5 \%$ at a potential of $+100 \mathrm{mV}(n=3$, data not shown). An anion permeability sequence of $\mathrm{P}_{\mathrm{Br}-}>\mathrm{P}_{\mathrm{Cl}-}>\mathrm{P}_{\mathrm{I}-}>\mathrm{P}_{\text {gluconate }}(n=5$, data not shown) was observed. These characteristics are in agreement with previous findings (2, 30-33). The current density obtained for COS cells transfected with M470 CFTR $(43.9 \pm 10.0 \mathrm{pA} / \mathrm{pF})$ was about twice as high as the current density obtained for COS cells transfected with V470 CFTR $(21.6 \pm 5.1 \mathrm{pA} / \mathrm{pF} ; P<0.05$, Fig. $3 \mathrm{~B})$. The functional properties of M470 and V470 CFTR were also studied in Xenopus oocytes by using a conventional two-microelectrode voltage clamp method. Again, larger membrane currents were obtained for oocytes that expressed M470 CFTR protein $(0.9 \pm 0.2 \mu \mathrm{mA}, n=5)$ compared with cells that expressed V470 CFTR protein $(0.5 \pm 0.04 \mu \mathrm{A}, n=11 ; P<0.05$; Fig. $3, C$ and $D)$.

The increase in current density for the M470 variant compared with V470 can either be explained by the presence of an increased number of CFTR proteins in the membrane of the cells, an increased open probability of the expressed channels, or a combination of these. Therefore, single-channel patchclamp analysis was also performed on COS cells that transiently expressed V470 or M470 CFTR protein (Fig. 4 A). A single-channel conductance of $5.0 \pm 0.9 \mathrm{pS}$ was obtained for
V470 $(n=5)$ and 5.6 $\pm 0.6 \mathrm{pS}$ for M470 CFTR protein $(n=6)$. The probability of the channels being open was almost twice as high for M470 CFTR $(0.45 \pm 0.05, n=6)$ than for V470 CFTR $(0.27 \pm 0.03, n=5, P<0.05$; Fig. $4 B)$. It can thus be concluded that the allele present at the polymorphic locus M470V affects gating of the CFTR channel.

T5 haplotypes. So far, the factors that determine the penetrance of T5 as a disease allele are unknown. Given our findings that particular alleles at polymorphic loci have functional consequences at the CFTR transcript or protein level, we wondered whether they would affect the penetrance of the T5 allele as a disease allele. T5 CFTR genes were derived from 1 PS-CF patient, 18 CBAVD patients, 13 parents of CF patients (their non-CF CFTR genes), and 5 random healthy fertile people. Due to lack of CFTR transcripts derived from these individuals, association studies were performed.

T5 was found on four different haplotypes (Table III). All T5 CFTR genes derived from parents of CF patients (5 paternal $[P<0.0002]$ and 8 maternal $\left.\left[P<10^{-5}\right]\right)$ and 4 out of 5 T5 CFTR genes derived from random fertile people $(P<0.003)$ were found on haplotype $\mathrm{F}$, while only $1 / 18$ T5 CFTR genes derived from a CBAVD patient was found on this haplotype background. Interestingly, based on the functional data mentioned above, haplotype $\mathrm{F}$ is associated with the most functional CFTR gene. Indeed, the highest proportion of exon 9+ CFTR transcripts is transcribed from this haplotype. Moreover, at the protein level this haplotype encodes channels with 
Table III. T5 Haplotypes

\begin{tabular}{lcccc}
\hline Haplotypes & CBAVD & Parents & Random & CF \\
\hline & $n=18$ & $n=13$ & $n=5$ & $n=1$ \\
F: TG11/T5/M470 & 1 & 13 & 4 & 0 \\
E: TG12/T5/V470 & 15 & 0 & 1 & 0 \\
G: TG13/T5/M470 & 2 & 0 & 0 & 0 \\
H: TG13/T5/V470 & 0 & 0 & 0 & 1
\end{tabular}

Haplotypes E-H were built from alleles found at the (TG)m, Tn, and M470V loci, respectively. CFTR genes were either derived from 1 PS$\mathrm{CF}$ patient, random fertile people, parents (five paternal and eight maternal) of CF patients (non-CF CFTR genes), or CBAVD patients. One haplotype E CFTR gene derived from a CBAVD patient, and 1 haplotype $\mathrm{G}$ and the haplotype H CFTR gene were sequenced over the complete coding region and the exon/intron junctions. For the remainder CBAVD patients, the complete CFTR coding region and exon/intron junctions were analyzed by denaturating gradient gel electrophoresis (9). No other mutations were found. The numbers of each haplotype found in the four groups of individuals are given.

higher intrinsic chloride transport activities. Of control T5 CFTR genes, haplotype $\mathrm{F}$ turned out to be most common.

The majority of the T5 CFTR genes derived from CBAVD patients (15/18), and $1 / 5$ derived from a random fertile person were found on haplotype $\mathrm{E}$. This haplotype was not found at all among the normal CFTR genes of CF parents (paternal, $P<0.002$; maternal, $P<0.0002$ ). This haplotype is associated with a less functional $C F T R$ gene: a lower proportion of exon $9+$ transcripts that will be translated into CFTR proteins with lower intrinsic chloride transport activities are associated with this haplotype. Haplotype $\mathrm{G}$ was found twice on CFTR genes derived from CBAVD patients. These haplotypes are known to result in a dramatic high proportion of exon 9- transcripts. Finally, one T5 CFTR gene was found on haplotype $\mathrm{H}$. This CFTR gene was derived from a 16-yr-old PS-CF patient who carried the $\Delta \mathrm{F} 508$ on his other CFTR gene. This haplotype carries the less functional V470 allele, and will generate a very low proportion of exon $9+C F T R$ transcripts.

\section{Discussion}

We have shown that some of the more common polymorphisms in the CFTR gene have consequences at the functional level. In agreement with previous studies (17), the nature of the allele present at the Tn locus determined the amount of exon9- transcripts. Moreover, in this study it was found that the (TG)m locus also affected the amount of exon 9- transcripts independently of the allele found at the Tn locus as illustrated for the T7 allele. A longer TG repeat would place the branchpoint A nucleotide of the lariat in a less favorable position for splicing. It should be noted that the qualitative and quantitative analysis was performed on samples derived from patients suffering from chronic nasal obstruction or sinusitis. In patients that present with milder pulmonary disease, such as in a small proportion of patients with disseminated bronchiectasis (11), CFTR mutations have been found. However, the patients studied here did not suffer from disseminated bronchiectasis or COPD. Moreover, no disease mutations could be identified. First, no mutation was found when screening for the most common classical CF mutations that represent $85 \%$ of all CF mutations in our population. The majority of patients that present with milder disease phenotypes carry a mild mutation on one CFTR gene and a severe, classical CF mutation on their second allele $(8-10,12)$. The fact that the CF carrier frequency is not different from that found in the control population argues against an involvement of CFTR in the pathology of these patients. Second, the rather frequent $3849+10 \mathrm{kbC} \rightarrow \mathrm{T}$ mutation found in milder patients was not detected, also arguing against an involvement of CFTR. Third, no disease mutations were found after sequencing exons 8-10 and their exon/intron junctions. Indeed, splice site or nonsense mutations (34) could result in skipping exon 9. Therefore, it is highly unlikely that the qualitative and quantitative differences found were caused by disease mutations.

By means of association studies of T5 CFTR genes, only the shortest TG repeat number was found in healthy individuals, and was never found in patients. This result strongly favors the hypothesis that this polymorphic locus affects the nature of CFTR. A (TG)12 repeat in combination with a T7 stretch, a (TG)11-T9 haplotype, or a (TG)13 repeat in combination with a T5 stretch, would indeed place the branchpoint nucleotide in the same less favorable position (17; Table II). Thus, both the alleles at the (TG)m and Tn loci determine the proportion of transcripts from which functional CFTR proteins can be translated, and thereby affect net chloride transport activity of CFTR-expressing cells.

The allele found at the M470V locus also affected CFTR. We found that M470 CFTR proteins have a 1.7-fold increased intrinsic chloride channel activity compared with V470 CFTR proteins. Also, differences were found in the biogenesis of these two CFTR proteins. The fully glycosylated form of M470 matured more slowly than V470. Whether the slower maturation of M470 CFTR is a result of its increased intrinsic chloride channel activity or vice versa, or is independent of it is not known.

Given our observations that alleles at polymorphic loci can affect CFTR at the transcript and/or protein level, it would be wise to study mutations on their respective haplotype background. This also holds for the mutations already studied (6). Indeed, while only a minority of the more than 720 CFTR disease mutations identified so far have been studied at the functional level, these studies have been performed irrespective of the haplotype background of these mutations.

Given the high frequency of the alleles at these polymorphic loci in individuals not affected by lung disease $(9,20)$, the allele present at each locus appears not to be deleterious by itself. However, the combination of particular alleles at these polymorphic loci does affect the amount of functional CFTR and can even lead to disease. Indeed, four different haplotype backgrounds for T5 CFTR genes were found. One of these (haplotype F) will generate the highest proportion of exon 9+ transcripts that will be translated into CFTR proteins with the highest intrinsic chloride transport activities. Only this fittest T5 haplotype background was found in fathers of $\mathrm{CF}$ patients, which could explain why these men do not have CBAVD. The other three T5 haplotype backgrounds were found in patients who carried a higher number of TG repeats. In view of the effect of the (TG)m locus on a T7 background on the proportion of exon $9+$ transcripts, and of the analogous modifications caused by (TG)m alleles on T5 CFTR genes (Table II), the in- 
volvement of the (TG)m locus in the penetrance of T5 as a disease mutation is obvious (haplotypes $F$ and $G$ only differ for the allele found at the (TG)m locus). Although the alleles found at the M470V locus affect the properties of CFTR, involvement of this locus in the penetrance of the T5 allele as a disease mutation was less clear than for the (TG)m locus. Indeed, for haplotype E, the presence of the (TG)12 allele might by itself be sufficient to make T5 penetrant as a disease allele. In one individual, however, the proportion of exon $9+$ transcripts derived from such a CFTR gene was found to be 0.28 (Table I). Given the low amount of CFTR that is required for normal chloride transport function $(35,36)$, this proportion is still considerable, suggesting that V470 is necessary for the penetrance of haplotype $\mathrm{E}$ as a disease haplotype. It is also interesting to note that the (TG)13/T5/M470 haplotype was found on CFTR genes derived from two CBAVD patients, while the (TG)13/T5/V470 haplotype was found on a CFTR gene derived from a PS-CF patient. Since these haplotypes only differed for the allele found at the M470V locus, these data again indicate a possible involvement of the M470V locus in the penetrance and severity of T5 as a disease allele. It should be noted, however, that the importance of the kinetics of CFTR maturation for overall CFTR-mediated chloride transport activity of cells that express CFTR has not been studied. It is therefore not known whether the slower maturation of M470 could compensate for its increased activity as a chloride channel, compared with V470 CFTR. However, in whole-cell recordings, both in COS cells and in oocytes, M470 was found to have about a twofold increased chloride transport activity compared with V470 CFTR, suggesting that the difference in maturation rate between M470 and V470 CFTR has no compensating effect. A larger number of T5 CFTR genes need to be studied before significant conclusions about the involvement of M470V on phenotypic expression can be drawn.

Apart from the fact that the nature of transcripts derived from a particular CFTR gene are affected by intragenic polymorphisms, a potential important observation was made during the course of the study. Indeed, our results suggest that the nature of these transcripts is also modulated by the CFTR gene in trans. The following significant inverse correlation was found: the proportion of exon 9- transcripts from haplotype A increased when the haplotype in trans produced a low proportion of exon 9- transcripts, and vice versa. To some extent, a lower or higher proportion of exon 9- transcripts derived from a particular CFTR gene was therefore compensated by the allele in trans. This compensation would further increase the complexity and variability by which a particular CFTR genotype confers a particular phenotype. This intriguing observation warrants further studies in order to confirm these findings, and to unravel the precise mechanisms involved and the physiological importance of this phenomenon.

At least one other polymorphic locus, (TG)m determines the partial penetrance and the severity of the T5 allele as a disease mutation. Such mutant $C F T R$ genes that harbor a particular combination of alleles and/or variants at polymorphic loci could be classified as polyvariant mutant $C F T R$ genes. In fact, one of the polyvariant mutant $C F T R$ genes ([TG]12/T5) now turns out to be the most frequent CBAVD CFTR mutant. Polyvariant $C F T R$ genes might also explain why no mutations can be detected in some $C F T R$ genes derived from patients (8-10, 21, 37). While there is evidence that the CF phenotype can be modulated by other genes, as has been shown in mice
(38), and/or by environmental factors, the role of these intragenic polymorphisms should not be underestimated.

Polymorphisms have previously been shown to modulate the phenotypic expression of true disease mutations such as $\mathrm{R} 117 \mathrm{H}$ (15). In the prion protein gene, the allele at the M129V polymorphic locus determines the fate of the N178D mutation, either as fatal familial insomnia or as a mutant gene that causes a subtype of familial Creutzfeldt-Jakob disease $(39,40)$. Rather than modulating the fate of a disease mutation such as $\mathrm{R} 117 \mathrm{H}$ in CFTR and N178D in the prion protein gene, our results show that even two or more polymorphic loci alone can act in concert with each other to result in insufficient or less functional CFTR protein.

Knowledge of the molecular basis of the partial penetrance of the T5 allele as a CBAVD mutation should improve genetic counseling. Genetic testing for additional polymorphisms now allows one to identify the high-risk T5 CFTR genes. On the other hand, involvement of polymorphisms further complicates genetic testing for a disease caused by more than $720 \mathrm{mu}$ tations. New technologies such as high-density DNA array assays will become necessary to provide quick, accurate, and complete analysis of any mutation or polymorphism in any gene in a particular individual (41). However, they will not be able to construct haplotypes to detect such polyvariant genes, which in many cases will require segregation analysis. Therefore, further improvements in mutation detection assays and in their applications will be required before a foolproof mutation-polymorphism detection system will be available.

Apparently innocent allelic variants affect the phenotypic expression of particular genes. Combinations of polymorphisms in different genes clearly contribute to the development of multifactorial diseases. The apolipoprotein E and $\alpha 1$-antichymotrypsin polymorphisms have been shown to be associated with late-onset familial and sporadic forms of Alzheimer's disease (42-44). Apolipoprotein E polymorphisms also predispose to vascular disease (45). HLA polymorphisms in combination with polymorphisms at other loci are associated with diabetes and autoimmune diseases (46). Polyvariant mutant genes and possibly combinations of them might also be involved in multifactorial diseases. Current knowledge of polymorphisms and their role in genetic diseases, however, is still very limited. It is clear, therefore, that genetic and functional studies of polymorphisms in genetic diseases will become of major interest in the future.

\section{Acknowledgments}

The expert technical assistance of Tom Willems, Annemie Bessems, and Marleen Willems is gratefully acknowledged. The pTG5960 vector was generously provided by Transgene S.A., Strasbourg, France. We also would like to thank Annick Thomas-Soumarmon for providing the HCF703 monoclonal antibody, Ludwine Messiaen for referring two CBAVD patients, and Christian Bossuyt for referring the CF patient. We are also grateful to Eric Legius who assisted in the statistical analysis of the data. We thank Het Vlaams Instituut voor de bevordering van het Wetenschappelijk-Technologisch onderzoek in de industrie for scholarships to Anne Vankeerberghen and Ingrid Reynaert. Harry Cuppens is a Postdoctoraal Navorser of the Onderzoeksfonds KULeuven.

These investigations have been supported by grant Levenslijn 7.0012.94 from the Fonds voor Wetenschappelijk Onderzoek-Vlaanderen, INSERM, and Association Française de Lutte contre la Mucoviscidose grants. 


\section{References}

1. Riordan, J.R., J.M. Rommens, B.S. Kerem, N. Alon, R. Rozmahel, Z. Grzelczak, J. Zielenski, S. Lok, N. Plavsic, et al. 1989. Identification of the cystic fibrosis gene: cloning and characterization of complementary DNA. Science. 245:1066-1073.

2. Bear, C.E., C. Li, N. Kartner, R.J. Bridges, T.J. Jensen, M. Ramjeesingh, and J.R. Riordan. 1992. Purification and functional reconstitution of the cystic fibrosis transmembrane conductance regulator (CFTR). Cell. 68:809-818.

3. Kerem, B.S., J.M. Rommens, J.A. Buchanan, D. Markiewicz, T.K. Cox, A. Chakravarti, M. Buchwald, and L.C. Tsui. 1989. Identification of the cystic fibrosis gene: genetic analysis. Science. 245:1073-1080.

4. The Cystic Fibrosis Genetic Analysis Consortium. 1994. Population variation of common cystic fibrosis mutations. Hum. Mutat. 4:167-177.

5. The Cystic Fibrosis Genetic Analysis Consortium. Cystic Fibrosis Mutation Data Base. http://www.genet.sickkids.on.ca/cftr/

6. Welsh, M.J., and A.E. Smith. 1993. Molecular mechanisms of CFTR chloride channel dysfunction in cystic fibrosis. Cell. 73:1251-1254.

7. Dumur, V., R. Gervais, J.M. Rigot, J.J. Lafitte, S. Manouvrier, J. Biserte, E. Mazeman, and P. Roussel. 1990. Abnormal distribution of CF $\Delta$ F508 allele in azoospermic men with congenital aplasia of epididymis and vas deferens. Lancet. 336:512

8. Chillón, M., T. Casals, B. Mercier, L. Bassas, W. Lissens, S. Silber, M.C. Romey, J. Ruiz-Romero, C. Verlingue, et al. 1995. Mutations in the cystic fibrosis gene in patients with congenital absence of the vas deferens. N. Engl. J. Med. 332:1475-1480.

9. Costes, B., E. Girodon, N. Ghanem, E. Flori, A. Jardin, J.C. Soufir, and M. Goossens. 1995. Frequent occurrence of the CFTR intron 8 (TG)n 5T allele in men with congenital bilateral absence of the vas deferens. Eur. J. Hum. Genet. 3:285-293.

10. Zielenski, J., P. Patrizio, M. Corey, B. Handelin, D. Markiewicz, R. Asch, and L.C. Tsui. 1995. CFTR gene variant for patients with congenital absence of vas deferens. Am. J. Hum. Genet. 57:958-960.

11. Pignatti, P.F., C. Bombieri, M. Benetazzo, A. Casartelli, E. Trabetti, L.S. Gilè, L.C. Martinati, A.L. Boner, and M. Luisetti. 1996. CFTR gene variant IVS8-5T in disseminated bronchiectasis. Am. J. Hum. Genet. 58:889-892.

12. Miller, P.W., A. Hamosh, M. Macek, Jr., P.A. Greenberger, J. MacLean, S.M. Walden, R.G. Slavin, and G.R. Cutting. 1996. Cystic fibrosis transmembrane conductance regulator (CFTR) gene mutations in allergic bronchopulmonary aspergillosis. Am. J. Hum. Genet. 59:45-51.

13. Highsmith, W.E., L.H. Burch, Z. Zhou, J.C. Olsen, T.E. Boat, A. Spock, J.D. Gorvoy, L. Quittell, K.J. Friedman, L.M. Silverman, et al. 1994. A novel mutation in the cystic fibrosis gene in patients with pulmonary disease but normal sweat chloride concentrations. N. Engl. J. Med. 331:974-980.

14. Sheppard, D.N., D.P. Rich, L.S. Ostedgaard, R.J. Gregory, A.E. Smith, and M.J. Welsh. 1993. Mutations in CFTR associated with mild-disease-form $\mathrm{Cl}^{-}$channels with altered pore properties. Nature. 362:160-164.

15. Kiesewetter, S., M. Macek, Jr., C. Davis, S.M. Curristin, C.S. Chu, C. Graham, A.E. Shrimpton, S.M. Cashman, L.C. Tsui, J. Mickle, et al. 1993. A mutation in CFTR produces different phenotypes depending on chromosomal background. Nat. Genet. 5:274-278.

16. Chu, C.S., B.C. Trapnell, J.J. Murtagh, Jr., J. Moss, W. Dalemans, S. Jallat, A. Mercenier, A. Pavirani, J.P. Lecocq, G.R. Cutting, et al. 1991. Variable deletion of exon 9 coding sequences in cystic fibrosis transmembrane conductance regulator gene mRNA transcripts in normal bronchial epithelium. EMBO (Eur. Mol. Biol. Organ.) J. 10:1355-1363.

17. Chu, C.S., B.C. Trapnell, S. Curristin, G.R. Cutting, and R.G. Crystal. 1993. Genetic basis of variable exon 9 skipping in cystic fibrosis transmembrane conductance regulator mRNA. Nat. Genet. 3:151-156.

18. Strong, T.V., D.J. Wilkinson, M.K. Mansoura, D.C. Devor, K. Henze, Y. Yang, J.M. Wilson, J.A. Cohn, D.C. Dawson, R.A. Frizzell, and F.S. Collins. 1993. Expression of an abundant alternatively spliced form of the cystic fibrosis transmembrane conductance regulator (CFTR) gene is not associated with a cAMP-activated chloride conductance. Hum. Mol. Genet. 2:225-230.

19. Delaney, S.J., D.P. Rich, S.A. Thomson, M.R. Hargrave, P.K. Lovelock, M.J. Welsh, and B.J. Wainwright. 1993. Cystic fibrosis transmembrane conductance regulator splice variants are not conserved and fail to produce chloride channels. Nat. Genet. 4:426-431.

20. Cuppens, H., H. Teng, P. Raeymaekers, C. De Boeck, and J.J. Cassiman. 1994. CFTR haplotype backgrounds on normal and mutant CFTR genes. Hum. Mol. Genet. 3:607-614.

21. Cuppens, H., P. Marynen, C. De Boeck, and J.J. Cassiman. 1993. Detection of $98.5 \%$ of the mutations in 200 Belgian cystic fibrosis alleles by reverse dot-blot and sequencing of the complete coding region and exon/intron junctions of the CFTR gene. Genomics. 18:693-697.

22. Jorissen, M., B. Van der Schueren, H. Van den Berghe, and J.J. Cassiman. 1989. The preservation and regeneration of cilia on human nasal epithelial cells cultured in vitro. Arch. Oto-rhino-laryngol. 246:308-314.

23. Teng, H., M. Jorissen, H. Van Poppel, E. Legius, J.J. Cassiman, and H. Cuppens. 1997. Increased proportion of exon 9 alternatively spliced CFTR transcripts in vas deferens compared with nasal epithelial cells. Hum. Mol. Genet. 6:85-90.
24. Gregory, R.J., S.H. Cheng, D.P. Rich, J. Marshall, S. Paul, K. Hehir, L. Ostedgaard, K.W. Klinger, M.J. Welsh, and A.E. Smith. 1990. Expression and characterization of the cystic fibrosis transmembrane conductance regulator. Nature. 347:382-386.

25. Jaspers, M., C. de Meirsman, E. Schollen, S. Vekemans, and J.J. Cassiman. 1994. Stable expression of VLA-4 and increased maturation of the $\beta 1-$ integrin precursor after transfection of CHO cells with $\alpha_{4 \mathrm{~m}}$ cDNA. FEBS Lett. 353:239-242.

26. Gallet, X., N. Benhabiles, M. Lewin, R. Brasseur, and A. Thomas-Soumarmon. 1995. Prediction of the antigenic sites of the cystic fibrosis transmembrane conductance regulator protein by molecular modelling. Protein Eng. 8: 829-834.

27. Droogmans, G., and B. Nilius. 1989. Kinetic properties of the cardiac T-type calcium channel in the guinea-pig. J. Physiol. 419:627-650.

28. Brezillon, S., F. Dupuit, J. Hinnrasky, V. Marchand, N. Kälin, B. Tümmler, and E. Puchelle. 1995. Decreased expression of the CFTR protein in remodeled human nasal epithelium from non-cystic fibrosis patients. Lab. Invest. 72:191-200

29. Lukacs, G.L., A. Mohamed, N. Kartner, X.B. Chang, J.R. Riordan, and S. Grinstein. 1994. Conformational maturation of CFTR but not its mutant counterpart $(\Delta \mathrm{F} 508)$ occurs in the endoplasmic reticulum and requires ATP. EMBO (Eur. Mol. Biol. Organ.) J. 13:6076-6086.

30. Drumm, M.L., H.A. Pope, W.H. Cliff, J.M. Rommens, S.A. Marvin, L.C. Tsui, F.S. Collins, R.A. Frizzell, and J.M. Wilson. 1990. Correction of the cystic fibrosis defect in vitro by retrovirus-mediated gene transfer. Cell. 62: $1227-1233$.

31. Anderson, M.P., R.J. Gregory, S. Thompson, D.W. Souza, S. Paul, R.C. Mulligan, A.E. Smith, and M.J. Welsh. 1991. Demonstration that CFTR is a chloride channel by alteration of its anion selectivity. Science. 253:202-205.

32. Tabcharani, J.A., X.B. Chang, J.R. Riordan, and J.W. Hanrahan. 1991. Phosphorylation-regulated $\mathrm{Cl}^{-}$channel in $\mathrm{CHO}$ cells stably expressing the cystic fibrosis gene. Nature. 352:628-631.

33. Fulmer, S.B., E.M. Schwiebert, M.M. Morales, W.B. Guggino, and G.R. Cutting. 1995. Two cystic fibrosis transmembrane conductance regulator mutations have different effects on both pulmonary phenotype and regulation of outwardly rectified chloride currents. Proc. Natl. Acad. Sci. USA. 92:6832-6836.

34. Dietz, H.C., D. Valle, C.A. Francomano, R.J. Kendzior, Jr., R.E. Pyeritz, and G.R. Cutting. 1993. The skipping of constitutive exons in vivo induced by nonsense mutations. Science. 259:680-683.

35. Trapnell, B.C., C.S. Chu, P.K. Paakko, T.C. Banks, K. Yoshimura, V.J. Ferrans, M.S. Chernick, and R.G. Crystal. 1991. Expression of the cystic fibrosis transmembrane conductance regulator gene in the respiratory tract of normal individuals and individuals with cystic fibrosis. Proc. Natl. Acad. Sci. USA. 88: 6565-6569.

36. Johnson, L.G., J.C. Olsen, B. Sarkadi, K.L. Moore, R. Swanstrom, and R.C. Boucher. 1992. Efficiency of gene transfer for restoration of normal airway epithelial function in cystic fibrosis. Nat. Genet. 2:21-25.

37. Claustres, M., M. Laussel, M. Desgeorges, M. Giansily, J.F. Culard, G. Razakatsara, and J. Demaille. 1993. Analysis of the 27 exons and flanking regions of the cystic fibrosis gene: 40 different mutations account for $91.2 \%$ of the mutant alleles in Southern France. Hum. Mol. Genet. 2:1209-1213.

38. Rozmahel, R., M. Wilschanski, A. Matin, S. Plyte, M. Oliver, W. Auerbach, A. Moore, J. Forstner, P. Durie, J. Nadeau, et al. 1996. Modulation of disease severity in cystic fibrosis transmembrane conductance regulator deficient mice by a secondary genetic factor. Nat. Genet. 12:280-287.

39. Goldfarb, L.G., R.B. Petersen, M. Tabaton, P. Brown, A.C. LeBlanc, P. Montagna, P. Cortelli, J. Julien, C. Vital, W.W. Pendelbury, et al. 1992. Fatal familial insomnia and familial Creutzfeldt-Jakob disease: disease phenotype determined by a DNA polymorphism. Science. 258:806-808.

40. Monari, L., S.G. Chen, P. Brown, P. Parchi, R.B. Petersen, J. Mikol, F. Gray, P. Cortelli, P. Montagna, B. Ghetti, et al. 1994. Fatal familial insomnia and familial Creutzfeldt-Jakob disease: Different prion proteins determined by a DNA polymorphism. Proc. Natl. Acad. Sci. USA. 91:2839-2842.

41. Chee, M., R. Yang, E. Hubbell, A. Berno, X.C. Huang, D. Stern, J. Winkler, D.J. Lockhart, M.S. Morris, and S.P.A. Fodor. 1996. Accessing genetic information with high-density DNA arrays. Science. 274:610-614.

42. Corder, E.H., A.M. Saunders, W.J. Strittmatter, D.E. Schmechel, P.C. Gaskell, G.W. Small, A.D. Roses, J.L. Haines, and M.A. Pericak-Vance. 1993. Gene dose of apolipoprotein E type 4 allele and the risk of Alzheimer's disease in late onset families. Science. 261:921-923.

43. Strittmatter, W.J., A.M. Saunders, D. Schmechel, M. Pericak-Vance, J. Enghild, G.S. Salvesen, and A.D. Roses. 1993. Apolipoprotein E: high-avidity binding to $\beta$-amyloid and increased frequency of type 4 allele in late-onset familial Alzheimer's disease. Proc. Natl. Acad. Sci. USA. 90:1977-1981.

44. Kamboh, M.I., D.K. Sanghera, R.E. Ferrell, and S.T. DeKosky. 1995. APOE*4-associated Alzheimer's disease risk is modified by $\alpha 1$-antichymotrypsin polymorphism. Nat. Genet. 10:486-488.

45. Davignon, J., R.E. Gregg, and C.F. Sing. 1988. Apolipoprotein E polymorphism and atherosclerosis. Arteriosclerosis. 8:1-21.

46. Todd, J.A. 1995. Genetic analysis of type 1 diabetes using whole genome approaches. Proc. Natl. Acad. Sci. USA. 92:8560-8565. 